\title{
AN EXPERIMENTAL INVESTIGATION OF A LOW SPEED LONG LINEAR INDUCTION MOTOR DIVIDED INTO SEVERAL STATORS CONNECTED IN SERIES
}

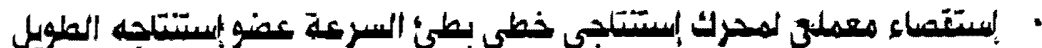

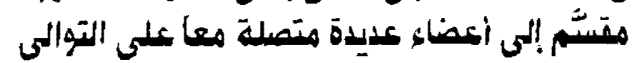

Dr. S. A. El-Drieny

Electrical Engineering Department, Faculty of Engineering, El-Mansoura University, El-Mansoura, Egypt

هلخص البحث :

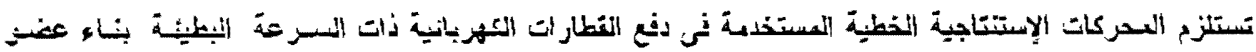

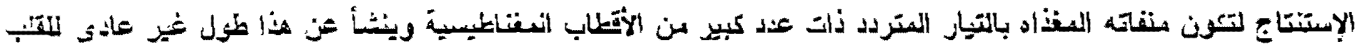

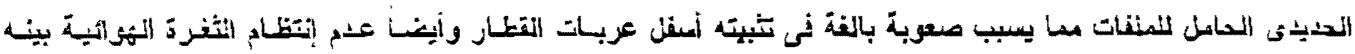

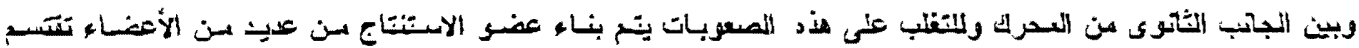

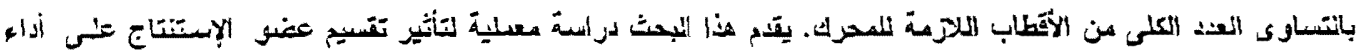

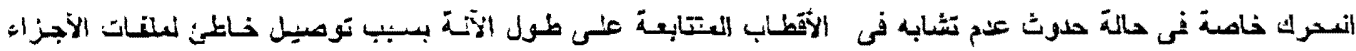

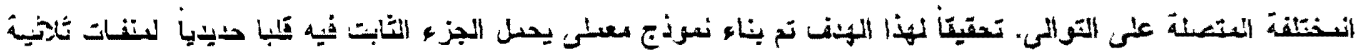

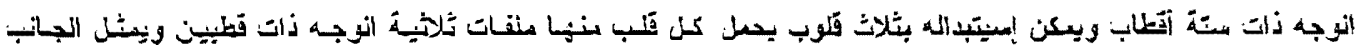

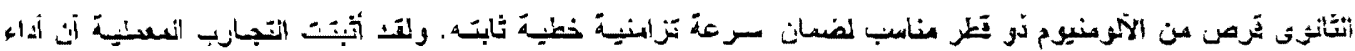

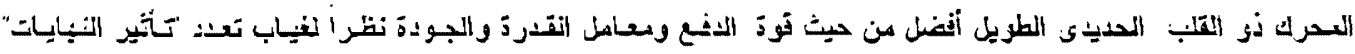

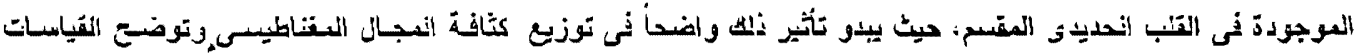

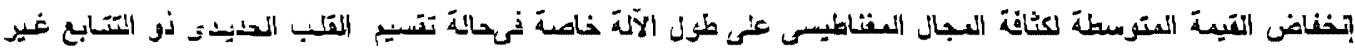

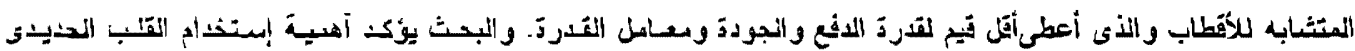

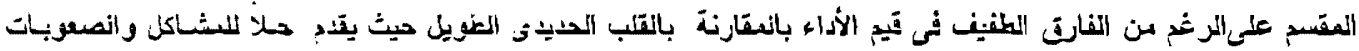

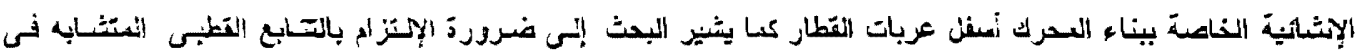

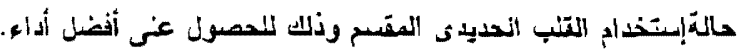

\section{ABSTRACT}

An experimental study of a linear induction motor whose stator is divided into short stators that are connccted in series is presented. The investigation includes a comparison of this motor with anotler motor having undivided stator. The present investigation is concerned with no-load and full-load conditions. the thrust, the power factor and the efficiency are reported under both constant current and voltage operations. Measurcinents of air gat hux over the length of the long stator and the three short divided stators are also presented. The cascade connection of three divided short stators for difterent distribution of phase nı.m.f.: namely the same polarity distrihution (N-S-N-S-N-S) and opposite polarity listribution is presented. 
The experimental results recommended the cascade connection wh the same distributiơn m.m. $f$. and a minimum distahce between the stators to yield free movement and reduce the entry and exit ends power loss. The experimental study aims to demonstrate the divided short stator and to solve the problem.regarding the suspension of long stator on the train to cope with steep siope and irregularities of the track.

\section{INTRODUCTION :}

Considerable interest has been developed in recent years in the use of linear induction motor as the propulsion for future high speed trains. The linear induction motor LIM provides simple and rigid structure. Because of the structural advantages, the LIM is considered as a suitable type of propulsion motor for both high and low speed -rains [1-G]. However. this application requires a good technique ror speed control and electrical braking due to frequent stops. In addition to some problems regarding the suspension of long primary on the train and difficulty to cope with steep slope and irregularities of the track. To solve the above problens a long stator LIM, divided into some short stators connected in series. is built in electrical engineering laboratory of El-Mansoura University, see rigure (1) and picture (1). Experimental investigation is concentrated on the performance, the thrust. the efficiency, and the power-factor under constant current and voltage operations. Measurements of air-gap rlux density over the length of stator under no-load is also presented. Also, the thrust is measured and compared in the two differences : the long stator divided into short ones, connecting in serles, and long stator which is undivided (LIM-A). The experimental results are used to understanding the LIM of long stator divided into short ones connected in series under load for different distribution of phase m.m. . . either in the same polarity distribution (N-S-N-S), (LIM-B), or in opposite polarity distribution of phase m.m. $f .(N-S-S-N),(L I M-C)$.

\section{DESCRIPTION OF THE PROTOTYPE MOTOR :}

A laboratory prototype motor is constructed to enable the detailed experimental studies. The model consists of two parts, see Fig.(1); a double-sided stator as the primary part : and an aluminum rotating disc as the secondary part. The disc is made of $7 \mathrm{~mm}$ thickness and fixed on an axle which is free to rotate between two bearlings. One stator side is wound for $s i x$ poles and fitted in $\mathrm{flat}, 80 \mathrm{~cm}$ long, laminated core. The other side of stator is divided into 3 several ones fitted in rlat - each $20 \mathrm{~cm}$ long and is wound for two poles. laminated core. Each stator is mounted in a rigid yoke assembly, and supported to a trapezoidal mild steel frame through two aluminum pieces: to minimize the magnetic leakage from the stator core to the frame. The centre line of each stator is at radius of $20 \mathrm{~cm}$ from the disc axis. Each stator consists of $12 \mathrm{~cm}$ stack of $0.35 \mathrm{~mm}$ silicon steel laminations with an inorganic interlaminar coating. These laminations are supported together with two mild steel plates of $5 \mathrm{~mm}$ thick, one at each side. The three short divided stators CSDSO each has 16 oper: slots are cut by a milling machine into the face of the assembled core. While the long stator CLSO has 40 open slots. The windings for both SDS and LS are double layer with two slots per polo per phase.

The facility of adjusting the air gap length had been considered. It is taken to be $14 \mathrm{~mm}$ between the two stator sides CSDS and LSO inclusive the thickness of an aluminum disc. The rotor disc diameter is chosen to be large compared Wth stator width. Accordingly, the 
peripheral speed of the dise is determined by disc periphery tangential to the stator centre 1 ine. The synchronous speed is $10 \mathrm{~m} / \mathrm{sec}$ at the centre of the stator, which corresponds to a pole pitch of $10 \mathrm{~cm}$.

Numerical design example of long stator (5), and 3 divided short ones is shown in Table (1). LIM $A$ is designed in a long stator structure (6-poles). LIM $B$ and LIM C consists of 2-poles stator respectively, which are divided LIM A with b-poles into three. The three divided short stators LIM B are connected in series and arranged in the same distribution of phase m. m. $f$. type $(N-S-N-S-N-S)$. While the three divided short stators LIM $C$ are connected in series and arranged in opposite polarity distribution of phase m. m. $f$. type $(N-S-S-N-N-S)$.

\section{EXPERIMENTAL RESULTS :}

The tests for measuring the magnetic flux distribution along the 3-divided short stators for both m.m.f. arrangement $(\mathrm{N}-\mathrm{S}-\mathrm{N}-\mathrm{S}$ ) and $(N-S-S-N)$ and the long stator are carried out under no load condition. Also the thrust, the efficiency and the power factor are measured under load condition in case of constant voltage and current operations for the above stators.

3.1. Magnetic Distribution Along The Stator Surface :

To measure the core fiux along, a search coil of 10 turns is wound and $f i x e d$ at the top of each tooth. The ends of the search coil are connected to the oscilloscope and the induced voltage can be measured. So, the flux which proportional to the induced voltage can be calculated. Figure (2) shows the flux distribution along the three short divided stators with the same polarity distribution of phase m.m. (. (LIM B). Figure (3) shows the flux distribution along the undivided stator (Long one LIM AJ. Figure (4) shows the $r l u x$ distribution with the opposite polarity distribution of phase m.m.f. CLIM C). It can be noticed from the figures that the flux is weakened at the entry ends due to the entry end effects then it bullt up gradually. There are dips and sharp rises due to the discreet distribution of ampere turns in the slots and reflected exit-end wave. So, due to several entry and exit ends, the average flux distribution in case of three divided short stator with the same polarity distribution of phase m.m. $f$. is smaller than the average flux distribution in case of long stator and greater than the average $f 1 u x$ distribution in case of three divided short stator with opposite polarity distribution of phase m.m. $r$. .

\section{2 Thrust and Efriciency :}

Measurements of the thrust is carried out by using a calibrated spring on one side of an attached wheel to the axle of the disc rotor and balanced with weights on the other side of the wheel. Figure (5) shows the measured thrust per meter under constant current for long stator (LIM A), 3 SDS (LIM B) and 3 SDS (LIM C). Figure (6) shows the measured thrust per meter under constant voltage for (LIM A). (LIM B) and (LIM C). It can be noticed that from the figures the maximum thrust developed in case of (LIM B), three divided short stator with the same polarity distribution of phase $\mathrm{m} . \mathrm{m} . \mathrm{f}$. is smaller than the maximum thrust developed in case of CLIM $A$ and greater than the maximum thrust developed in case of (LIM C) the opposite polarity distribution. Generally the maximum thrust developed in case of current source is higher than the maximum thrust developed in case of vol tage source. 


\section{CONCLUSTON :}

Building and testing of both long stator LIM (A) with 6 poles and. three short stators (each has 2 -poles) has resulted in an under standing the overall behaviour and characteristics under no-load and load conditions. By use of this racility, the thrust, efficiency and air-gap flux along long stator and three divided short stators were investigated under constant current and voltage operations.

The laboratory prototype motor is sufficiently flexdble to examine the cascade connection of the three divided short stators for different arrangement distribution of phase m.m.f., either in the same polarity distribution $(N-S-N-S-N-S)$ or in opposite polarity distribution of phase m.m.f. (N-S-S-N-N-S).

The results show that undivided stator (i.ong Stator) gives high normal thrust by about $10 \%$ rather than the divided one. But the problem regarding the suspension of long stator on the train pushing the designers of such type of LIM prefer the undivided short stator regarding the reduction of the thrust by about $10 \%$ than the long stator. Attention must be considered on cascade connection of several short stators, because the experimental results give high thrust by $10 \%$ in case of the same polarity distribution rather than the opposite polarity distribution.

The experimental tests pointed out that high thrust can be obtained under constant current operation than under constant voltage operation. Generally the efriciency is too bad in case of several divided short stators due to several existence of entry and exit ends power less. rather than of long stator.

The advantage of suspension of several short stators on the train to cope with steep slope and irregularities of track is essential for. practical application regardless the reduction of the thrust or efficiency by $10 \%$

The reasonable distance between short stators to maintain the continues free movement and to reduce the entry and exit ends power loss is not to increase by about half the pole pitch.

\section{REFERENCES :}

[1] S. Nonaka and T. Higuchi. : "On the design of single-sided Linear induction Motors for propulsion of Maglev Vehicles". Proc. of Tnt. Conf. on Maglev Transport' 85 pp 45-52 Sep. 85.

(2) A. Odendahi and $K$. Sattler. "The behaviour of series connection of two 1 inear induction motors with predicted motor distances". Proc. of Int Conf. on Elect. Machine PP 125-135. Sep. 1980.

(3) 5 Nonaka and $N$. Fujii, : "Three dimensional analysis of high-speed Linear Induction Motor with finite iron dimension". Trans. IEE Japan No. 100-B, 7 pp $413-120$. Jul 1990. Elect. Eng. Japan Vol 100, 4 pp 42-50 Jul. /Aug. 1990.

14] S. Nonaka, K. Yoshida and $K$. Ogawa. : Magnetic fields in high speed Linear Induction Motors taking into account finite length of. primary cores". Proc. of Int. Conf. on Electrical Machine pP $75-83$ September 1980 . 
[5] S.A. EL-Drieny, : An experimental investigation of a low speed - double sided linear induction motor", Bulltin of Faculty of: Engineering El-Mansoura University Vol. 11 . No.2. Decémber 1986.

[6] M. I wamoto, S. Sakaba, K. Kitagawa and G. Utsami, :"Experimental and theoretical study of high speed single sided linear induction motors", IEE Proc. Vol. 128. No.6, Nov. 1981.

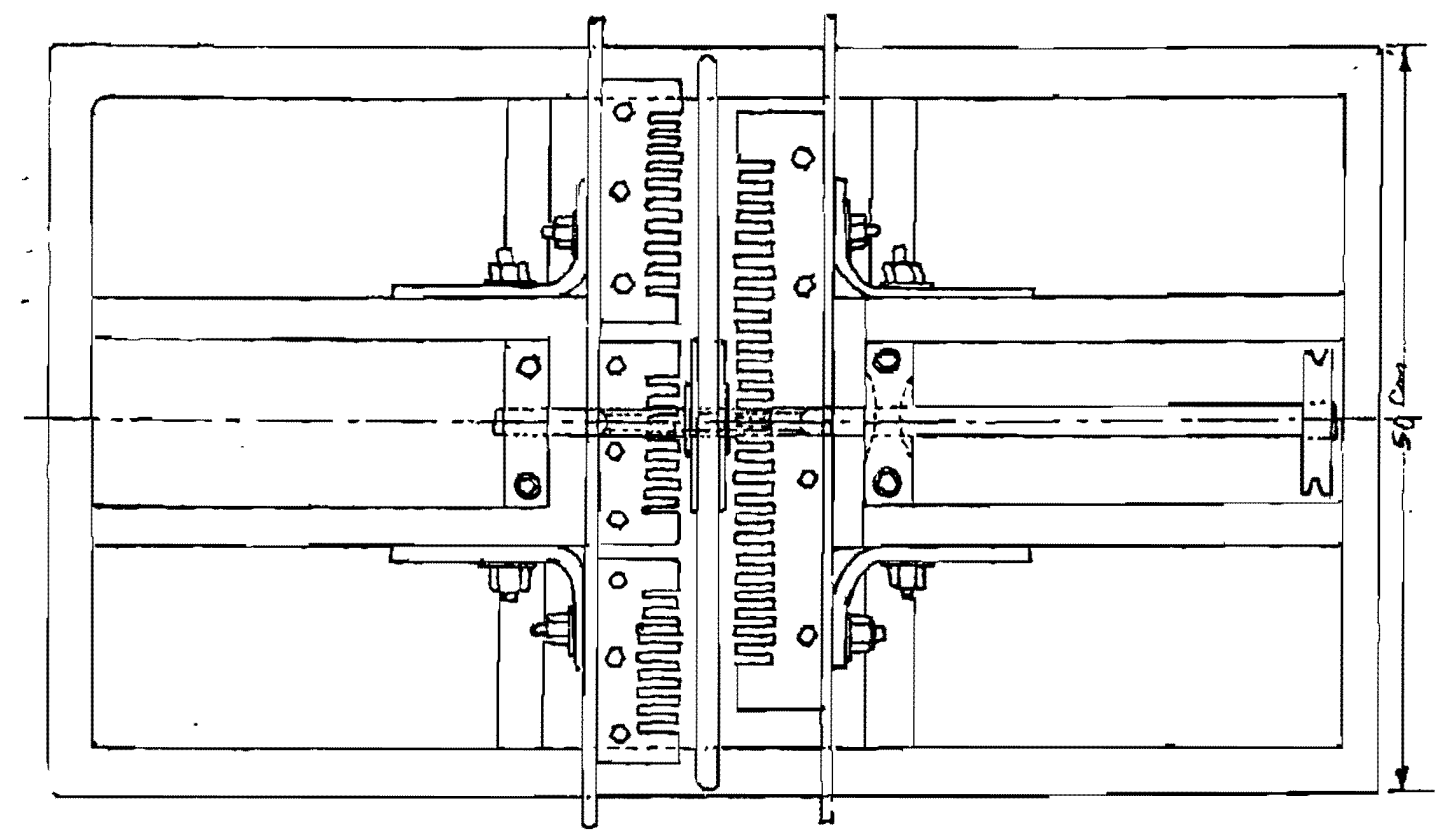

Fig. (1) : Construction of LIM Rig. 
Table (1) : Jesign Example

\begin{tabular}{|c|c|c|}
\hline \multirow{2}{*}{$P A R A M E=E$ S } & \multicolumn{2}{|c|}{ Numerals } \\
\hline & LIM $\therefore A$ & LIM (B\&C) \\
\hline Number it poises per one $i x$ & $\because$ & 2 \\
\hline 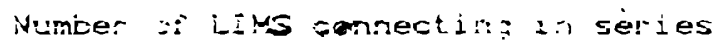 & $\leq$ & .3 \\
\hline Primar' =ore length per zne irM & 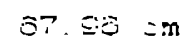 & $27.98 \mathrm{~cm}$ \\
\hline Weigh: : : copper per on: i::1 & $: 1.20$ & $5.70 \mathrm{Kg}$ \\
\hline Voltagir jor phase & $320 \%$ & $220 \mathrm{~V}$ \\
\hline Fr eque::-:! & $50 \quad 1 z$ & $50 \mathrm{~Hz}$ \\
\hline Syncher.:-is spasod & $10 \mathrm{~m} / \mathrm{s}$ & $10 \mathrm{~m} / \mathrm{s}$ \\
\hline Thrus: & $493 \mathrm{~kg} . \mathrm{m}$ & $493 \mathrm{~kg} \cdot \mathrm{m}$ \\
\hline Number $=:$ pinases & 3 & 3 \\
\hline Rated $=:-:$ : ent & $7.5 \mathrm{~A}$ & $7.5 \mathrm{~A}$ \\
\hline Pole p1:...: & $100 \mathrm{~mm}$ & $100 \mathrm{~mm}$ \\
\hline Slot.po: aphase & 2 & 2 \\
\hline Slot wis: $\therefore$ & $10 \mathrm{~mm}$ & $10 \mathrm{~mm}$ \\
\hline Tooth $:=:$ & ธ. $56 \mathrm{~mm}$ & 6. $66 \mathrm{~mm}$ \\
\hline Stack he: $\because$ & $73 \mathrm{~mm}$ & $73 \mathrm{~mm}$ \\
\hline Over hari? : trech & $51.5 \mathrm{~mm}$ & $51.5 \mathrm{~mm}$ \\
\hline Number $\therefore$. Ar r:s, coil & 114 & 120 \\
\hline Core wi $=$ - i. & $11.5 \mathrm{~cm}$ & $12.6 \mathrm{~cm}$ \\
\hline 'Jinding & $\begin{array}{l}\text { double } \\
\text { layer }\end{array}$ & $\begin{array}{l}\text { double } \\
\text { layer } \therefore\end{array}$ \\
\hline Phase spr id & 60 Deg. & 60 Deg. \\
\hline Eurrent $=-151 \mathrm{tg}$ & $4 \Delta \mathrm{mm}^{2}$ & $4 A \mathrm{~mm}^{2}$ \\
\hline Hi riding isctor & 0.827 & 0.827 \\
\hline $\begin{array}{l}\text { Eross section area } 0^{*} \text { conductor } \\
\text { Paking iuctor }\end{array}$ & $\begin{array}{l}1.59 \mathrm{~mm}^{2} \\
0.6\end{array}$ & $\begin{array}{l}1.59 \mathrm{~mm}^{2} \\
0.6\end{array}$ \\
\hline
\end{tabular}


Mansoura Englneering Journal, Yol. 20, No. 1, March 1995

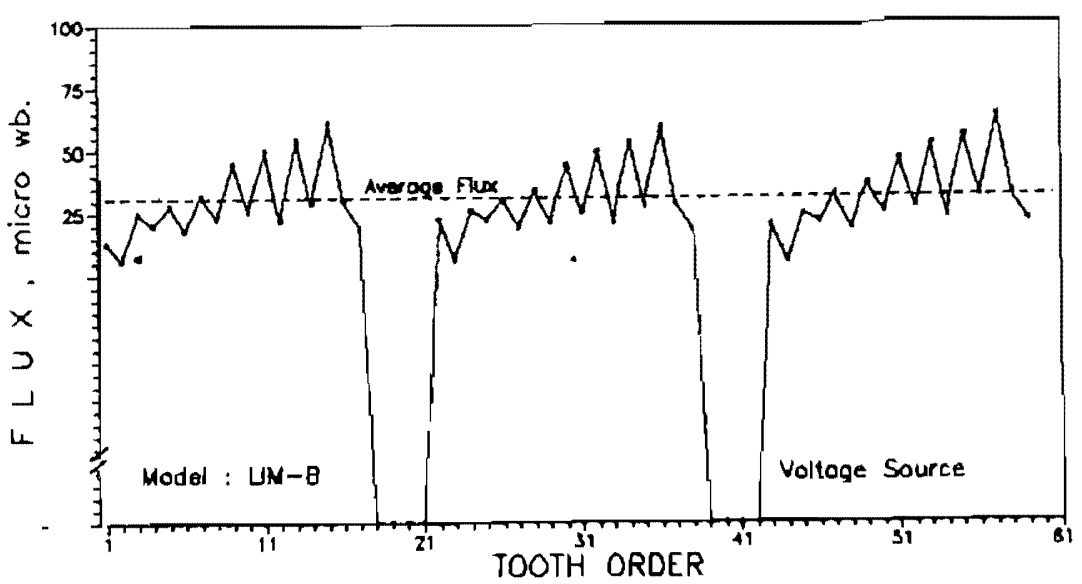

Fig.(2): Flux Distribution Along The 3 Short Divided Stators With The Same Polarlty Distribution of Phase $\mathrm{mm} \mathrm{m}$. (LIM B).

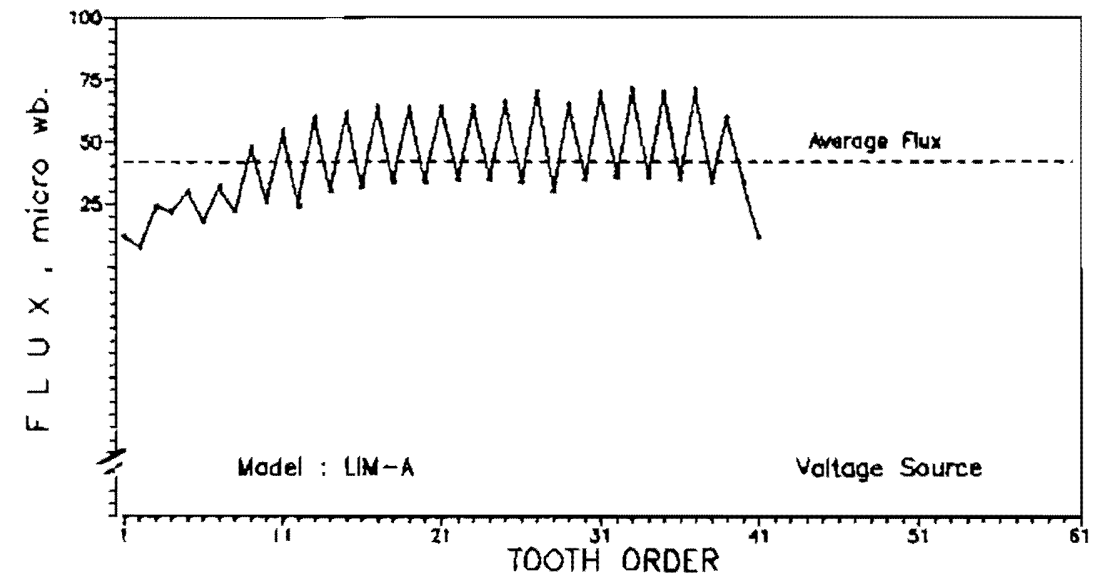

Fig.(3): Flux Distribution Alang The Undivided Stator (LIM A).

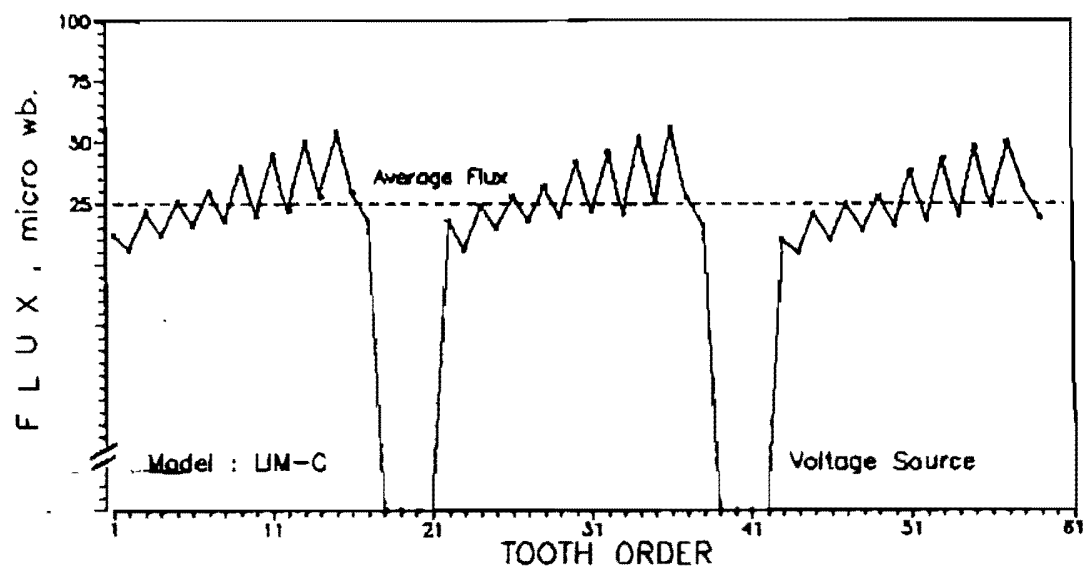

Fig.(4): Flex Distribution Alang The 3 Short Divided Stators With The Opposite Polarity Distrib- 

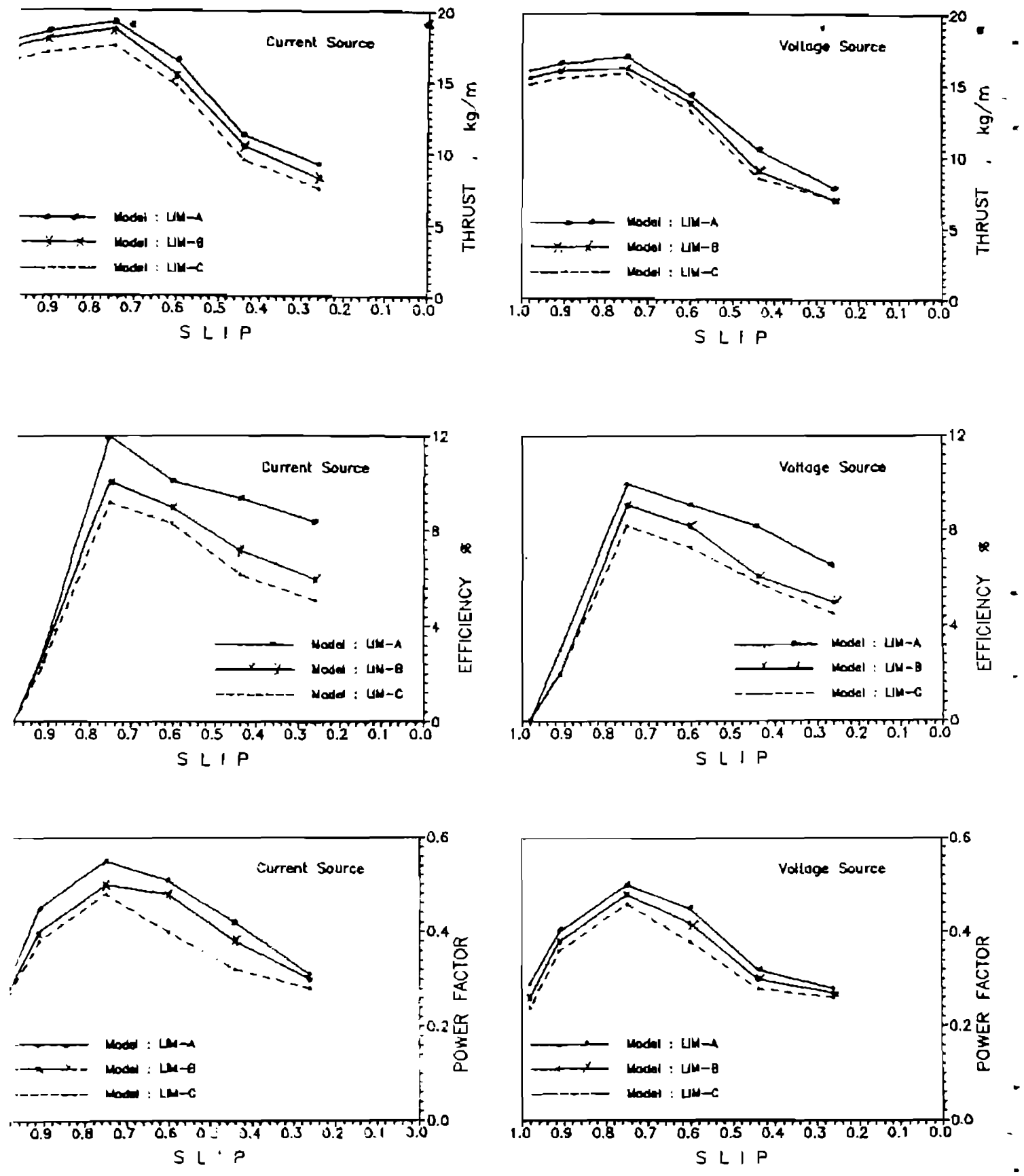

(5): Measused Trirlist/in. Efriciency \% a.id P.F. under Constant Current, For LIKA LIM $B$ and LIM C.

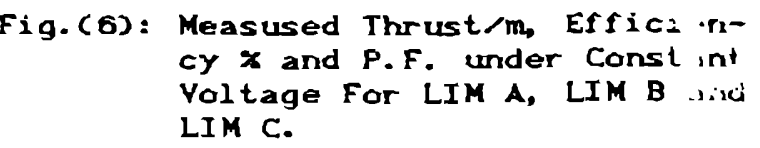


Mansoura Engineering Journal, Vol. 20, No. 1, March 1995
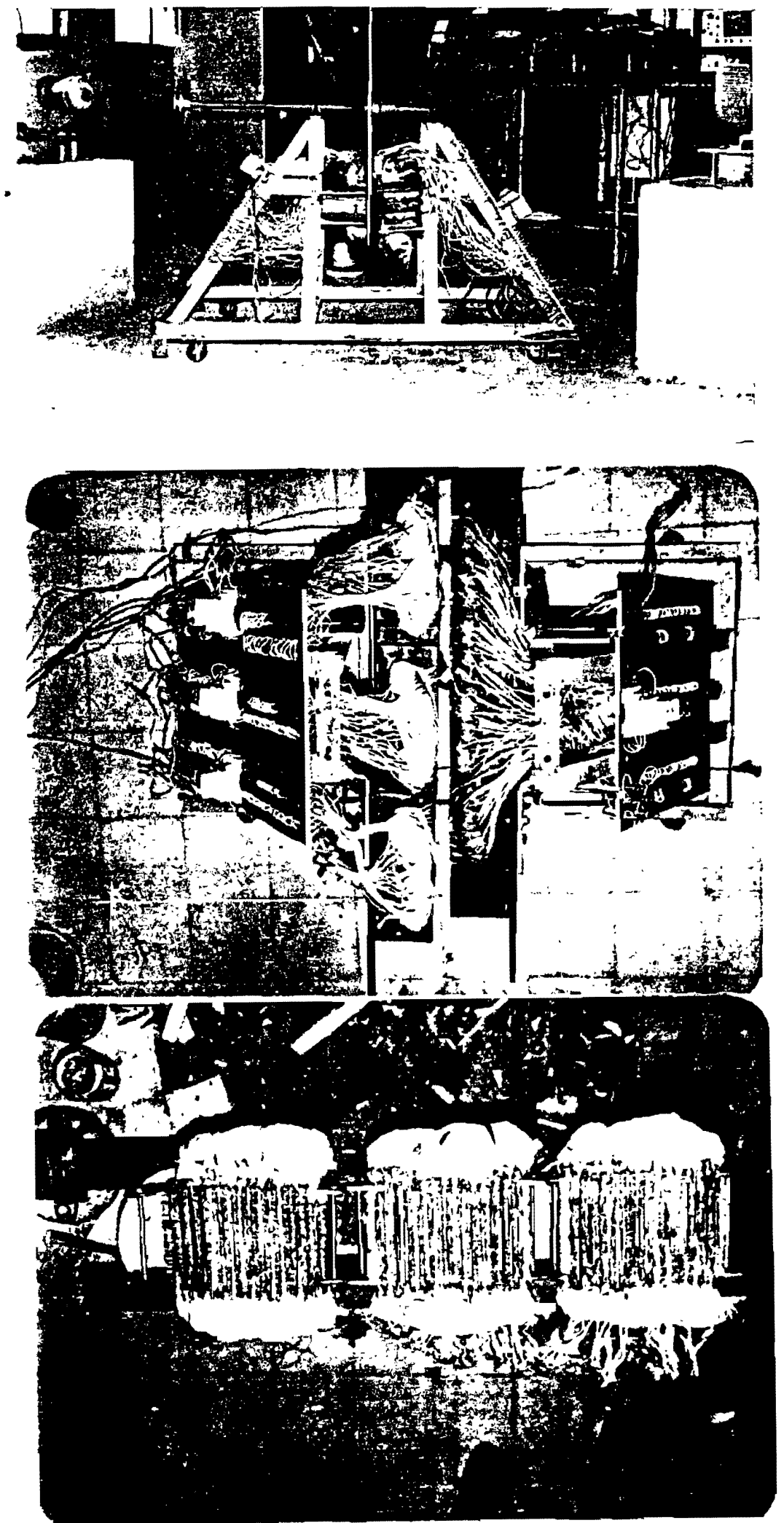

Picture (1): The Laboratory LIM Prototype Motor. 